\title{
Disease Milestone Instance Date
}

National Cancer Institute

\section{Source}

National Cancer Institute. Disease Milestone Instance Date. NCI Thesaurus. Code C162267.

The date of a specific disease milestone. 